the complete oxidation of the metal. The film is invisible and, so far as the writers are aware, no direct evidence of its existence on aluminium ordinarily treated has been adduced."

Until very recently we were in agreement with Seligman and Williams regarding the absence of direct evidence. During the course of experiments made with the object of studying the properties of films produced on aluminium by the Bengough anodic process, we found it was possible to isolate the films by the following method:

The aluminium, preferably in the form of thin sheet, is cut into narrow strips, and one or more of these strips is heated in a tube in an atmosphere of dry hydrogen to a temperature of $300^{\circ} \mathrm{C}$. Dry hydrogen chloride is then passed through the tube. The metallic aluminium exposed at the cut edges of the strips reacts with the hydrogen chloride to form aluminium chloride, which sublimes and deposits in the cooler parts of the tube. Ultimately all the metallic aluminium is so removed and the surface films remain, together with some of the impurities in the aluminium.

By the above method it was found possible to obtain a film from normal commercial aluminium sheet. The natural film liberated in this way was extremely delicate, tended to curl, and was small in amount, but appeared to be continuous.

H. SutTon.

J. W. W . Wir.tstrop.

Royal Aircraft Establishment, South Farnborough, Hants, April 7.

\section{Formation of Organic Acids from Sugars by Aspergillus niger.}

UNDER the above title we recently showed (J.Chem. Soc., 1927, 200) that when Aspergillus niger is grown on citric acid as sole source of carbon, the formation of acetone, malonic acid, and glyoxylic acid can be demonstrated. The production of citric acid from potassium saccharate and the mould may be detected, under careful control, by Denigés' test and by oxidation to acetone. It appears, therefore, that saccharic acid may possibly be an intermediate product in the formation of citric acid from glucose by Aspergillus niger, as was suggested by Franzen and Schmitt in the case of the citric acid in plants (Berichte Deutschen Chem. Ges., 1925, 58, 222).

This view has now received further support from our recent observation that when $A$. niger is grown on glucose as sole source of carbon, the solution contains saccharic acid, which may be isolated as the potassium hydrogen salt. This has been identified (1) by titration with standard alkali, (2) by determination of potassium, and (3) by determination of thallium in the corresponding thallium hydrogen salt. Apart from the observation of Grüss (Jahrbücher für wiss. Botanik, 1926, 66, 155, 171, 177) that saccharic acid is formed by the action of the yeasts Anthomyces Reukaufii and Amphiernia rubra on glucose, this would appear to be the only recorded instance of the production of this acid by micro-organisms.

Grüss employed a medium containing glucose and traces of peptone, asparagine, potassium tartrate, and mineral salts, and the saccharic acid was identified microscopically as the cæsium hydrogen salt.

$$
\begin{aligned}
& \text { F. CHALLENGER. } \\
& \text { V. SUBRAMANIAM. } \\
& \text { T. K. WALKER. }
\end{aligned}
$$

Municipal College of Technology and the University, Manchester.

\section{The Supposed Law of Flame Speeds.}

In NAtURE of Feb. 12, p. 238, Dr. W. Payman and Prof. R. V. Wheeler reply to my letter in the issue of Jan. 8. They agree that deviations from the law of speeds may be expected if one of the combustibles in a complex mixture interferes with the burning of another, but claim that the deviations are small.

The examples $\mathrm{I}$ gave were carbon monoxidehydrogen-air, and carbon disulphide--ethyl ether-air mixtures, but similar effects are obtained when ether is replaced by any one of a large number of combustibles. With regard to the first example, I quote Dr. Payman (Jour. Chem. Soc., 1919, I I 5, 1456) : ". . . in the present research the maximum speed of uniform movement of flame in mixtures of carbon monoxide and air is found to be about half the value calculated, making use of the values determined for hydrogen-air and hydrogen-carbon monoxide--air mixtures." Such a difference between the calculated and experimental values would argue more than a small deviation from the law of speeds.

The same conclusion can be drawn from my own determinations of speed of flame in carbon disulphide - second combustible-air mixtures. Here the 'effective' speeds of the carbon disulphide-air mixtures, as calculated from the complex mixtures, are often less than half those directly determined. This phenomenon can scarcely be ascribed to a ' cool' flame, as it occurs even with a carbon disulphideair mixture proportioned to give perfect combustion. An account of these experiments is being prepared for publication.

\section{Caledonia Road, Saltcoats.}

\section{The Origin of the Earth's Surface Structure.}

Some further explanation of certain points in our letter in NATURE of April 9 on the above subject is desirable.

Our argument concerning the mode of origin of the earth's surface structure does not turn upon whether dunite or eclogite forms the deeper substratum; for these substances differ but little in radioactivity and are alike in density. The uranium and thorium content of dunite (Phil. Mag., May 1924) is considerably below that of the plateau basalts, and their content of potassium is practically nil. Hence, whether eclogite or dunite occupies the depths, we are justified in concluding that density and radioactivity vary inversely in the earth's outer regions: the intrinsic density increasing and the radioactivity diminishing downwards. If Prof. Holmes's suggestion that the lower part of the continents is dioritic in character is correct (NATURE, Oct. 23, 1926), the rule still applies. Our preference for eclogite as occupant of the depths is founded on the simplification involved, seeing that this substance is to be expected therein as a piezocrystalline form of basaltic magma; for such it undoubtedly is.

While our contention that seismic evidence is not opposed to the existence of deep-seated eclogite is true, it is also true that its presence has not as yet received the same experimental support as the presence of dunite has received. We believe the experiments of Adams and Gibson have not so far been extended to eclogite. There is much to justify the expectation that when they are so extended the results will be similar.

J. JoLY.

J. H. J. POOLE.

No. 3001, VoL. 119] 